\title{
Multistep batch-flow hybrid synthesis of a terbinafine precursor
}

\author{
Tamás Hergert ${ }^{1,2} \cdot$ Béla Mátravölgyi $^{1} \cdot$ Róbert Örkényi $^{1,3} \cdot$ János Éles $^{4} \cdot$ Ferenc Faigl $^{1}$
}

Received: 29 April 2021 / Accepted: 6 July 2021 / Published online: 26 July 2021

(C) The Author(s) 2021

\begin{abstract}
A three-step batch-flow hybrid process has been developed for an expeditious synthesis of the enynol key intermediate of antifungal terbinafine. This procedure involves consecutive organometallic steps without the necessity of any in-line purification: after a metalation by $n$-butyllithium, a selective addition of the lithium salt was elaborated followed by a Grignard reaction resulting in a high yield of 6,6-dimethylhept-1-en-4-yn-3-ol. Moreover, as an alternative to tetrahydrofuran, cyclopentyl methyl ether was used as solvent implementing a safe, sustainable, yet selective synthetic process. Even on a laboratory-scale, the optimized batch-flow hybrid process had a theoretical throughput of $41 \mathrm{~g} / \mathrm{h}$. Furthermore, the newly developed process provides an efficient synthesis route to the key-intermediate, while making acrolein obsolete, minimizing side-products, and enabling safe and convenient scale-up.
\end{abstract}

Keywords Multistep organometallic reaction $\cdot$ Batch-flow hybrid synthesis $\cdot$ Terbinafine $\cdot$ Enynol

\section{Introduction}

Allylic alcohols are versatile building blocks for organic synthesis as they permit a wide range of ensuing transformation [1-3]. There are only a few procedures described in the literature $[4,5]$; therefore, the continuous synthesis and modification of functionalized allyl alcohols are still challenging. Allylic enynols are important constituents, especially in the synthesis of active pharmaceutical ingredients having antiviral and antimycotic activities [6, 7]. In an original industrial-scale synthetic route (Scheme 1), an organometallic step is followed by the addition of acrolein to synthetize

Tamás Hergert

tamas.hergert@gmail.com; https://www.linkedin.com/in/tamashergert-4207a434/

1 Department of Organic Chemistry and Technology, Budapest University of Technology and Economics, Budafoki Str. 8, Budapest H-1111, Hungary

2 Present address: ThalesNano Energy Ltd, Graphisoft Park, Záhony Str. 7, Budapest H-1031, Hungary

3 Present address: Evonetix Ltd, Coldham's Business Park, 9a, Norman Way, Cambridge CB1 3LH, UK

4 Chemical Works of Gedeon Richter Plc, Gyömrői Str. 19-21, Budapest H-1103, Hungary 6,6-dimethylhept-1-en-4-yn-3-ol $\mathbf{3}$. Enynol 3 is the key intermediate of terbinafine, best-known under the brand name of Terbisil@ or Lamisil@ [8].

The allylamine-containing terbinafine is an orally and topically active antifungal agent with an activity that inhibits the biosynthesis in fungi of the principal sterol, ergosterol, by the inhibition of squalene epoxidase [9-12]. Chemical synthesis of compound 3 includes addition of acrolein after the metalation of 3,3-dimethyl-but-yne $\mathbf{2}$ by $n$-butyllithium at low temperature $[8,13-15]$. There are obvious safety issues associated with the use of $n$-butyllithium as it is a moisture-sensitive, flammable reagent that may lead to hotspot generation, runaway reactions, possible explosions, and side-product formation. Moreover, acrolein is highly flammable, volatile, and extremely carcinogenic.

The pressing need for sustainable chemical reactions has raised a demand for novel, economic-friendly processes that expand the conventional synthetic toolbox and generate minimal waste. Continuous flow processing is considered to be a "hot topic" due to its versatile and unique control over key reaction parameters [16]. Accordingly, industrial interest can be envisioned as multistep syntheses [17], automatically optimized processes [18] or end-to-end production in a refrigerator-sized system [19] of active pharmaceutical ingredients is an engaging and promising area. Although several examples of flow applications exist [20], there is still an unceasing need for effective, state-of-the-art solutions. 


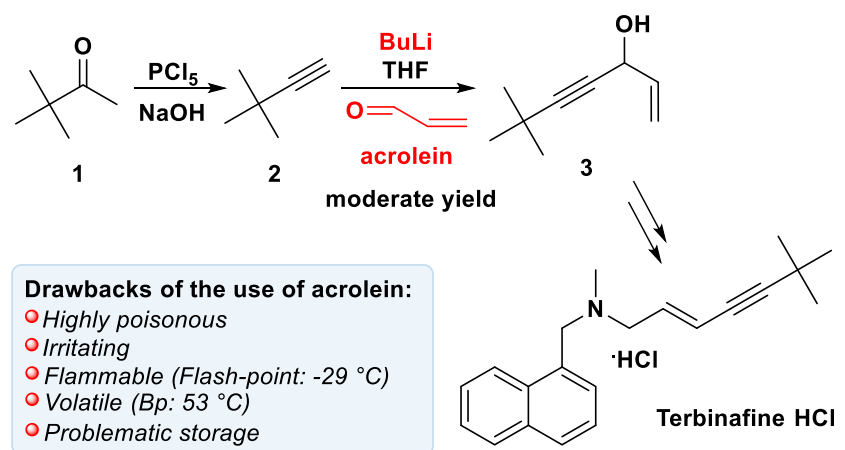

Scheme 1 Currently used industrial-scale synthetic route towards the active pharmaceutical ingredient of terbinafine $\mathrm{HCl}$ salt

In many cases, such as continuous flow hydrogenation, ozonolysis, or organometallic reactions, the use of flow equipment has proven its value and can bring doubtless advantage for synthetic chemists [21]. Among the clear benefits of flow chemistry, such as rapid heat dissipation, efficient mixing, selectivity, reproducibility, in-line analysis and purification or easily accessible industrial scale-up, the possibility of using in situ generated hazardous or unstable intermediates poses one of the greatest significances [22]. Syntheses of formerly "forbidden" intermediates due to safety reasons, such as diazo compounds, hydrazine, azides, phosgene, cyanides, and other chemicals could be used with relatively low risk owing to flow techniques [23].

Multistep batch-flow hybrid synthesis combines the best of both synthetic techniques, as they offer unique advantages in different systems, and combining them enables the widest range of chemistry to be carried out $[24,25]$. In this study, a highly selective batch procedure was coupled with flow chemistry to obtain a remarkably productive batch-flow hybrid process. This multistep organometallic reaction sequence resulted in the valuable enynol precursor of antifungal terbinafine without any in-line purification.

Only a few researchers addressed the issue of the synthesis of 1-alkynyl-aldehyde 4, out of which the most common synthetic strategy involved the addition of polar organometallics after activation [26-28]. Based on the results of Yamaguchi et. al., lithium acetylenides could react with esters at $-78^{\circ} \mathrm{C}$ in presence of boron trifluoride etherate. In case of aliphatic esters, ketones can be obtained in good yields [29]. In other synthetic protocols for the synthesis of the aldehyde type 4, organometallic derivatives of alkyl acetylenes were reacted with $N, N$-dimethylformamide as electrophile resulting in moderate yields [27, 30-33]. These conventional batch reactions cope with several safety issues, due to their hazardous nature, the high reactivity of reagents even at low temperatures, thus the need for careful handling of these chemicals and special circumstances are inevitable. Apart from the replacement of acrolein, the aim was to develop an efficient and robust process, which could be scaled-up to industrial-scale.

\section{Results and discussion}

\section{Three-step batch methodology}

The main objective of this research was to abolish the use of acrolein. Therefore, a two steps organometallic synthesis of key intermediate $\mathbf{3}$ was proposed and systematically investigated. In this paper we present the preparation of 4,4-dimethylpent-2-ynal 4 (Table 1) from 3,3-dimethylbutyne 2 followed by addition of vinylmagnesium bromide to 4 (Table 2).

Initial studies were made for the addition of the lithiated 3,3-dimethyl-butyne on ethyl formate to form aldehyde 4 . There are apparent selectivity issues with adding the formate to the solution of the metallated butyne dropwise. To avoid the high level of the dialkylated by-product 5 formation, reverse dispensing was required (Table 1/entry 1), i.e. the dropwise addition of the lithiated intermediate $\mathbf{2} \mathbf{L i}$ to the ethyl formate at $-78^{\circ} \mathrm{C}$ was significantly more selective.

In an attempt to analyze the applied solvent and the solubility of the system, the commonly used completely water-miscible tetrahydrofuran was replaced. In the case of methyl tert-butyl ether (MTBE), a suspension was obtained e v e n w h e n u s i n g $N, N, N^{\prime}, N^{\prime}{ }^{\prime}, N^{\prime}$ '-pentamethyldiethylenetriamine (PMDTA) that could only be dissolved by using additional $20 \%$ hexane (Table $1 /$ entry 1). Under the reaction conditions used, two compounds were observed: the expected product 4 and the dialkylated alcohol $\mathbf{5}$, which was resolved by switching to pure hexane. It was also found that raising the temperature and applying an excess of ethyl formate did not help to increase either the selectivity or the yield (entry 2 to 5).

2-Methyltetrahydrofuran (2-MeTHF) being a greener alternative to tetrahydrofuran seemed like a promising choice. Since 2-MeTHF is produced from renewable resources, it offers both economical and environmentally friendly advantages over tetrahydrofuran such as lower peroxide formation, easier to dry, has limited miscibility in water $(14 \mathrm{~g} / 100 \mathrm{~g}$ at $23{ }^{\circ} \mathrm{C}$ ), and a higher boiling point $\left(80^{\circ} \mathrm{C}\right)$ [34, 35]. Using 2-methyltetrahydrofuran did not require PMDTA to get the solution clear and the desired enynol 4 was synthesized in excellent yield and selectivity (Table 1/entry 6).

Another remarkable environmentally friendly alternative to tetrahydrofuran and tert-butyl methyl ether is cyclopentyl methyl ether (CPME) manufactured via a $100 \%$ atom economical reaction [36]. Due to its unique composition, which resists the formation of peroxides, CPME improves significantly process safety and in addition to its broad usefulness in many organometallic reactions, it provided better yields and higher selectivity as compared to tetrahydrofuran. CPME is only miscible with water to a very small extent $(1.1 \mathrm{~g} / 100 \mathrm{~g}$ at $23{ }^{\circ} \mathrm{C}$ ), thus it can be dried easier than THF or 2-MeTHF and 
Table 1 Optimization of the addition of lithio 3,3-dimethyl-butyne (2. Li) to ethyl formate

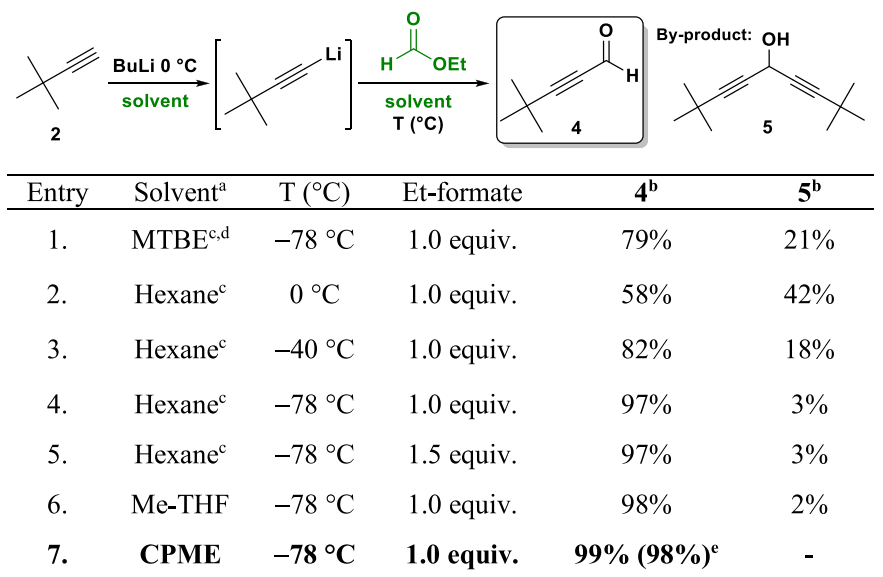

[a] MTBE: methyl tert-butyl ether, Me-THF: 2-methyltetrahydrofuran, CPME: cyclopentyl methyl ether. [b] Determined by GC with a Restek Rtx-5 fused column: $t_{R}(4)=3.46 \mathrm{~min}, \mathrm{t}_{\mathrm{R}}(\mathbf{5})=6.16 \mathrm{~min}$. [c] PMDTA was used as an additive to ensure solubility of all intermediates. [d] Additional hexane was necessary to get clear solution $(0.2 \mathrm{~mL}$ hexane was added to $1.0 \mathrm{~mL}$ MTBE). [e] Yield was determined using internal standard method (dodecane)

as a rich azeotrope with water its recovery can be realized effectively [37]. With regard to the synthesis development and scale-up, these properties are advantageous in the case of industrial applicability of sensitive organometallic reactions such those using butyllithium. In our optimization study, CPME was found to be the best solvent leading to excellent conversion $(98 \%$, determined by GC using internal standard method) without the formation of any diynol by-product 5 (Table 1/entry 7).

In order to investigate the next addition step by vinylmagnesium bromide, we kept 2-MeTHF as solvent option next to CPME since good results have also been obtained in it. Hexane itself was not appropriate due to the fact that the Grignard reagent was insoluble in it. Employing the freshly prepared 4 without any purification from the previous step proved to be feasible giving 6,6-dimethylhept-1-en-4-yn-3-ol $\mathbf{3}$ as the main component of the reaction mixture.

Although using 2-MeTHF as solvent a small decrease in selectivity of the aldehyde-forming step was detected in the case of one-pot implementation, compared to the previous one-step process (Table 1/entry 6), again a larger amount (13\%) of by-product was formed, but the overall product 3 ratio proved to be still high (Table 2/entry 1 to 2). At $0{ }^{\circ} \mathrm{C}$ already, a minor excess of the Grignard reagent was enough to form the alcohol $\mathbf{3}$ as main product. The best results were obtained in cyclopentyl methyl ether, 6,6-dimethylhept-1-en-4-yn-3-ol 3 could be formed with good conversion (88\%) and high selectivity (entry 3 ). Switching to the use of methyl formate in case of the aldehyde-formation step instead of the ethyl analogue, led to lower yields (entry 4), and $26 \%$ of the dialkylated by-product was observed.

\section{Batch-flow hybrid process}

After having optimized both steps in batch mode, we transferred the process into continuous-flow platform using syringe pumps. Based on the results of the preliminary batch tests, we envisioned a three-step consecutive organometallic process.

Table 2 Optimization of the addition of vinylmagnesium bromide to the aldehyde 4

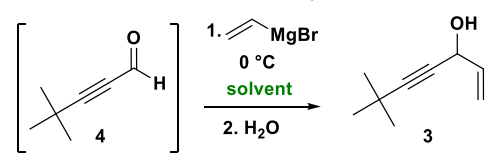

\begin{tabular}{cccccc}
\hline Entry & Solvent & Vinyl-MgBr & $\mathbf{4}^{\mathrm{a}}$ & $\mathbf{5}^{\mathrm{a}}$ & $\mathbf{3}^{\mathrm{a}}$ \\
\hline 1. & Me-THF & 1.5 equiv. & $4 \%$ & $13 \%$ & $83 \%$ \\
2. & Me-THF & 1.2 equiv. & $5 \%$ & $5 \%$ & $90 \%$ \\
3. & CPME & $\mathbf{1 . 2}$ equiv. & $\mathbf{1 \%}$ & $\mathbf{1 \%}$ & $\mathbf{9 8 \%}(\mathbf{8 8 \%})$ \\
$4^{\mathrm{c}}{ }^{\mathrm{b}}$ & CPME & 1.2 equiv. & $15 \%$ & $26 \%$ & $52 \%$
\end{tabular}

[a] Determined by GC with a Restek Rtx-5 fused column: $\mathrm{t}_{\mathrm{R}}(\mathbf{4})=3.46 \mathrm{~min}, \mathrm{t}_{\mathrm{R}}(\mathbf{5})=6.16 \mathrm{~min}, \mathrm{t}_{\mathrm{R}}(\mathbf{3})=4.49 \mathrm{~min}$. [b] Yield was determined using internal standard method (dodecane). [c] Instead of ethyl formate, the methyl analogue was used in the aldehyde (4) formation 
Initially, our aim was to analyse the selective synthesis of the aldehyde intermediate 4 . The metalation was carried out at $0^{\circ}$ $\mathrm{C}$ by butyllithium and the next addition step at $-78{ }^{\circ} \mathrm{C}$. Although the batch process worked well, according to the results measured by gas chromatography, between flow conditions only $6 \%$ aldehyde could be detected next to the starting 3,3-dimethylbutyne $\mathbf{2}$. After investigating several settings of conditions, the selectivity did not increase, thus we decided to elaborate a batch-flow hybrid process, namely to do the metalation under batch conditions following by a continuous addition of ethyl formate to obtain the desired intermediate of 4 .

Multistep batch-flow hybrid synthesis combines the best of both synthetic techniques, as they offer unique advantages in different systems and combining them enables the widest range of chemistry to be carried out $[16,38]$. Although continuous flow technology offers several unique solutions for synthetic reactions, the question to use this technique for a chemical transformation or not should be kept in mind. In many cases a batch-flow hybrid solution can mean the golden middle and a widely applicable, mixed toolbar could enable the efficient multistep production of various heterocycles and APIs.

Our continuous flow study began by analysing the aldehyde-forming step. First, we investigated the role of the residence time by changing the flow rate and the temperature next to a lower concentration (Table 3/entry 1 to 3 ).

To assure an inert system, dry THF was flowed (3 reactor volume) through the device to remove traces of water. Metalation was carried out in a Schlenk tube at $0{ }^{\circ} \mathrm{C}$ and it was pumped via a syringe-needle-fitted tubing through a Suba-Seal ${ }^{\circ}$ septa. The solution of ethyl formate was prepared in a similar Schlenk tube and Y-junction was used for mixing. Best result (46\% of 4) was obtained at lower temperature and flow rate, but we could not enhance the selectivity further, a significant amount of dialkylated by-product was always formed.

In order to find the reason of the notable by-product formation it was assumed that such a low concentration and using moderate flow-rates the metalated 3,3-dimethylbutyne 2 could not meet ethyl formate to the extent necessary, namely only a poor mixing can be realized. It is well-known that at low flow rates the fluid tends to move without lateral mixing resulting in laminar flow and diffusion only occurs between surfaces of the layers. Perfect mixing can be achieved in the tube only if the Reynolds number is at least 2300 , that can be only reached in a common 1/16" OD ( $0.5 \mathrm{~mm}$ ID) tubing by applying at least $16 \mathrm{~mL} / \mathrm{min}$ flow rate $[16,22,39]$. To facilitate the encounter of reagents other promising option could be the raising of concentration. Indeed, when tested a higher $1.0 \mathrm{M}$ starting concentration the selectivity almost doubled (Table 3/entry 4 to 9). Surprisingly, it turned out that carrying out the addition step at $-20^{\circ} \mathrm{C}$ ended in the best result. As can
Table 3 Optimization of the aldehyde-forming step in continuous flow system

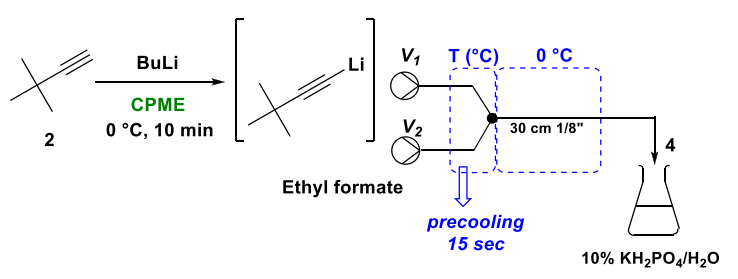

\begin{tabular}{ccccc}
\hline Entry $^{\mathrm{a}}$ & $\begin{array}{c}\mathrm{V}_{1,2} \\
(\mathrm{~mL} / \mathrm{min})\end{array}$ & $\mathrm{T}$ & $\mathbf{4}^{\mathrm{b}}$ & $\mathbf{5}^{\mathrm{b}}$ \\
\hline $1 .^{\mathrm{c}}$ & 0.5 & $-78{ }^{\circ} \mathrm{C}$ & $46 \%$ & $54 \%$ \\
$2 .^{\mathrm{c}}$ & 1 & $-78{ }^{\circ} \mathrm{C}$ & $30 \%$ & $70 \%$ \\
$3^{\mathrm{c}}$ & 0.5 & $-40{ }^{\circ} \mathrm{C}$ & $32 \%$ & $68 \%$ \\
$4 .^{\mathrm{d}}$ & 1 & $-78{ }^{\circ} \mathrm{C}$ & $80 \%(70 \%)^{\mathrm{e}}$ & $20 \%$ \\
$5 .^{\mathrm{d}}$ & 1 & $-40{ }^{\circ} \mathrm{C}$ & $86 \%$ & $14 \%$ \\
$\mathbf{6 .}^{\mathrm{d}, \mathrm{e}}$ & $\mathbf{1}$ & $-\mathbf{2 0}{ }^{\circ} \mathrm{C}$ & $\mathbf{9 4 \%}(\mathbf{8 8} \%)^{\mathrm{f}}$ & $\mathbf{6 \%}$ \\
$7 .^{\mathrm{d}}$ & 0.5 & $-20{ }^{\circ} \mathrm{C}$ & $82 \%$ & $18 \%$ \\
$8 .^{\mathrm{d}}$ & 1.25 & $-20{ }^{\circ} \mathrm{C}$ & $91 \%$ & $9 \%$ \\
$9 .{ }^{\mathrm{d}}$ & 5 & $-20{ }^{\circ} \mathrm{C}$ & $90 \%$ & $10 \%$ \\
\hline
\end{tabular}

[a] Metalation was carried out at $0{ }^{\circ} \mathrm{C}$. Asia Flow Chemistry Syringe Pump was used. 1.0 equiv. ethyl formate was used. [b] Determined by GC with a Restek Rtx-5 fused column: $t_{R}(4)=3.46 \mathrm{~min}, t_{R}(5)=6.16$ min. [c] The starting concentration was $0.2 \mathrm{M}$. [d] The starting concentration was $1.0 \mathrm{M}$. [e] Retention time in the case of $1 \mathrm{~mL} / \mathrm{min}$ flow rate: $\mathrm{t}_{\mathrm{R}}: 42 \mathrm{~s}$. [f] Yield determined with internal standard method (dodecane)

be seen from the table (entry 6), 4,4-dimethylpent-2-ynal $\mathbf{4}$ could be synthetized with $88 \%$ conversion next to outstanding selectivity (94\%) and this value does not decrease with increasing the flow rate, which is very promising for a possible industrial application.

Under these optimized continuous flow conditions, we were curious if the last organometallic step, the Grignard reaction can be attached to the process or not. To our delight, we successfully obtained the desired 6,6-dimethylhept-1-en-4-yn-3-ol 3 and immediately in good selectivity and yield (Table 4/entry 1). There was no noticeable negative effect of a higher flow rate (entry 2). An increase in the amount of divinyl by-product 6 was only observed when an excess was used from vinylmagnesium bromide (entry 3).

A multicomponent reaction was also envisioned for further optimisation, which however, worked only with moderate yield (Table 4/entry 4). In this process we added the Grignard reagent to the previously lithiated 3,3-dimethylbutyne $\mathbf{2}$ and by using only two flow channels we reacted this mixed solution with the one containing only ethyl formate. The amount of the divinyl by-product 6 significantly increased.

The highest final yield was obtained for a system setup (Scheme 2) with two Y-junctions, but it must be mentioned 
Table 4 Addition of vinylmagnesium bromide to aldehyde 4 in continuous flow

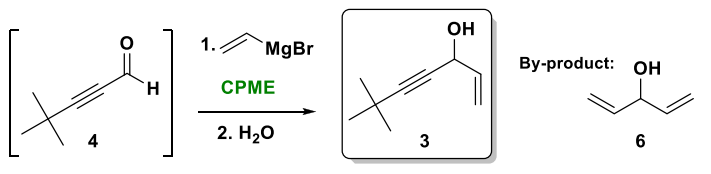

\begin{tabular}{ccccccc}
\hline Entry $^{\mathrm{a}}$ & $\begin{array}{c}\mathrm{V}_{1,2} \\
(\mathrm{~mL} / \mathrm{min})\end{array}$ & $\begin{array}{c}\mathrm{V}_{3} \\
(\mathrm{~mL} / \mathrm{min})\end{array}$ & $\mathbf{4}^{\mathbf{b}}$ & $\mathbf{5}^{\mathbf{b}}$ & $\mathbf{3}^{\mathbf{b}}$ & $\mathbf{6}^{\mathbf{b}}$ \\
\hline $1 .^{\mathrm{c}}$ & $\mathbf{1}$ & $\mathbf{2}$ & $\mathbf{3 \%}$ & $\mathbf{6 \%}$ & $\mathbf{8 2 \%}(\mathbf{8 0} \%)^{\mathbf{d}}$ & $\mathbf{9 \%}$ \\
2. & 5 & 10 & $2 \%$ & $6 \%$ & $81 \%$ & $11 \%$ \\
$3 .^{\mathrm{e}}$ & 1 & 2 & $3 \%$ & $5 \%$ & $73 \%$ & $19 \%$ \\
$4{ }^{\text {e,f }}$ & 1 & - & $<1 \%$ & $7 \%$ & $38 \%$ & $54 \%$
\end{tabular}

[a] Metalation was carried out at $0{ }^{\circ} \mathrm{C}$, addition at $-20^{\circ} \mathrm{C}$. The initial concentration was $1.0 \mathrm{M} .1 .0$ equiv. ethyl formate and 1.2 equiv. vinylmagnesium bromide was used. $\mathrm{V}_{1,2}$ : flow rates of $\mathbf{2}$ and ethyl formate, $\mathrm{V}_{3}$ : flow rate of Grignard-reagent solution. [b] Determined by GC with a Restek Rtx-5 fused column: $\mathrm{t}_{\mathrm{R}}(\mathbf{4})=3.46 \mathrm{~min}, \mathrm{t}_{\mathrm{R}}(\mathbf{5})=6.16 \mathrm{~min}, \mathrm{t}_{\mathrm{R}}(\mathbf{3})=4.49 \mathrm{~min}, \mathrm{t}_{\mathrm{R}}(\mathbf{6})=2.69 \mathrm{~min}$. [c] Retention time in the case of $1 \mathrm{~mL} / \mathrm{min}$ flow rate: $\mathrm{t}_{\mathrm{R}}: 71 \mathrm{~s}$. [d] Yield determined with internal standard method (dodecane). [e] 1.5 equiv. vinylmagnesium bromide was used. [f] Multicomponent reaction process: 1 . vessel: lithiated 3,3-dimethyl-butyne plus vinylmagnesium bromide $\left(\mathrm{V}_{1}\right)$; 2. vessel: ethyl formate $\left(\mathrm{V}_{2}\right)$ in CPME solvent

that by using these types of passive mixers and tubing, perfect mixing cannot be achieved in low overall concentrations and flow rates. Micromixers provide a wide range of solutions [40] for this problem but their size limitation remained still their disadvantage. It was crucially important during our reactions to enable good mixing of the reagents in order to achieve high selectivity and yield; therefore, dynamic mixers shall be considered in future applications.

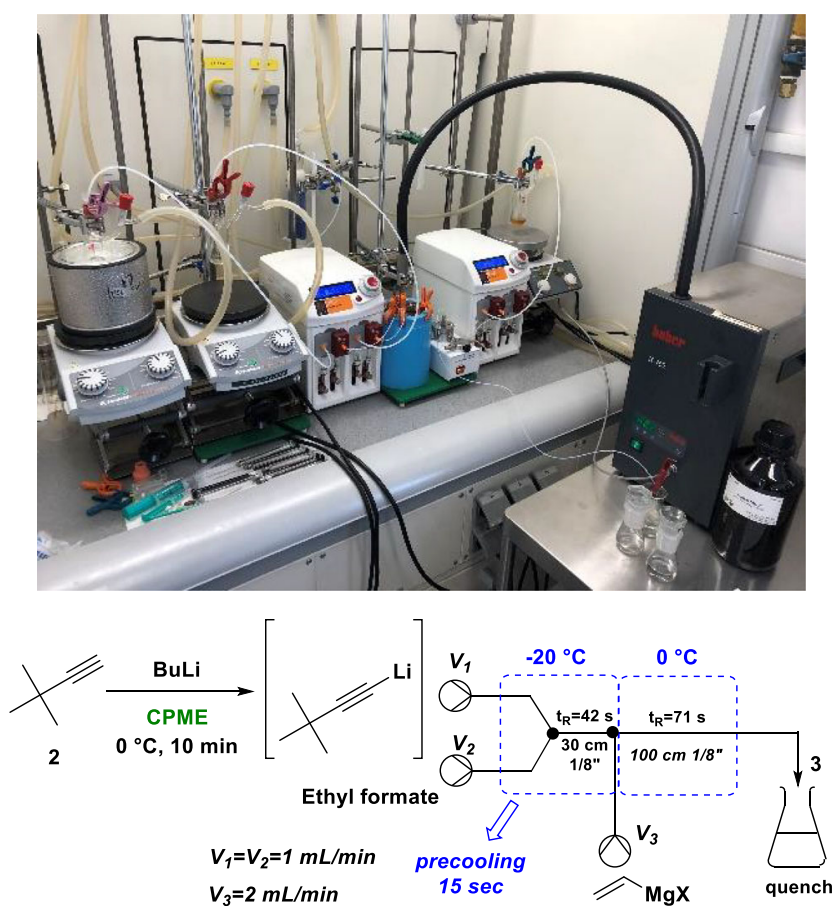

Scheme 2 Optimized three-step batch-flow hybrid process of the key intermediate $\mathbf{3}$ of terbinafine

\section{Experimental section}

\section{General}

All starting materials and anhydrous solvents were purchased from commercial sources and were used without further purification. Anhydrous solvents were stored over $4 \AA$ molecular sieves, except for anhydrous THF which was stored over sodium wire. The batch reactions and the first step of the batch-flow hybrid synthesis were carried out in Schlenk-flasks under a dry nitrogen atmosphere. Routine ${ }^{1} \mathrm{H}$ and ${ }^{13} \mathrm{C}$ spectra were recorded with a Bruker DRX 500 spectrometer. The chemical shifts $(\delta)$ are reported in parts per million (ppm) and the coupling constants $(J)$ in Hz. NMR Spectroscopy was performed in deuterated chloroform $\left(\mathrm{CDCl}_{3}\right)$ with tetramethylsilane (TMS) as internal and the chemical shift scale was referenced to the $1 \mathrm{H}$ or $13 \mathrm{C}$ signals of the internal TMS at $0.00 \mathrm{ppm}$. GC measurements were performed on an Agilent ${ }^{\circledR} 6890$ GC-FID chromatograph (Agilent, Santa Clara, CA, USA), using a $15 \mathrm{~m} \times 0.18 \mathrm{~mm}$ Restek, Rtx-5 column with a film thickness of $0.20 \mu \mathrm{m}$. The developed GC oven temperature program starts at $40{ }^{\circ} \mathrm{C}$ for $1 \mathrm{~min}$, followed by programming at $25^{\circ} \mathrm{C} / \mathrm{min}$ up to $300{ }^{\circ} \mathrm{C}$ and a final period at $300{ }^{\circ} \mathrm{C}$ (isothermal) for $10 \mathrm{~min}$. The temperature of the injector was set to $290{ }^{\circ} \mathrm{C}$ and of the FID detector to $300{ }^{\circ} \mathrm{C}$. The carrier gas was $\mathrm{N}_{2}$. In the case of flow steps, the steady state was verified by regular sampling and parallel gas chromatographic measurements.

\section{Batch procedure for the synthesis of 4,4-dimethylpent-2-ynal (4)}

To a stirred solution of 3,3-dimethylbutyne $(2,10.0 \mathrm{mmol})$ in dry cyclopentyl methyl ether $(6 \mathrm{~mL})$ butyl lithium $(2.5 \mathrm{M}$ in 
hexane, $4.00 \mathrm{~mL}, 10.0 \mathrm{mmol}$ ) was added at $0{ }^{\circ} \mathrm{C}$, under nitrogen atmosphere. The obtained mixture was stirred for $10 \mathrm{~min}$ and it was added dropwise to the cyclopentyl methyl ether $(10 \mathrm{~mL})$ solution of ethyl formate $(0.81 \mathrm{~mL}, 10.0 \mathrm{mmol})$ at $-78^{\circ} \mathrm{C}$ under inert conditions. After $10 \mathrm{~min}$ stirring, the reaction mixture was allowed to warm up to room temperature. $10 \% \mathrm{KH}_{2} \mathrm{PO}_{4}$ solution $(30 \mathrm{~mL})$ was added to the mixture and was extracted with CPME $(3 \times 20 \mathrm{~mL})$. The combined organic layers were dried over anhydrous $\mathrm{Na}_{2} \mathrm{SO}_{4}$. Purification was performed by fractionated vacuum distillation to yield $\mathbf{4}$ (atm., $\left.130-132{ }^{\circ} \mathrm{C}\right)$ as a pure colorless oil $(0.96 \mathrm{~g}, 87 \%) . \delta \mathrm{H}$ $\left(500 \mathrm{MHz}, \mathrm{CDCl}_{3}\right) 9.19(\mathrm{~s}, 1 \mathrm{H}), 1.31(\mathrm{~s}, 9 \mathrm{H}) \mathrm{ppm} . \delta \mathrm{C}$ $\left(126 \mathrm{MHz}, \mathrm{CDCl}_{3}\right)$ 177.3, 91.8, 67.8, 30.6 (3C), $25.5 \mathrm{ppm}$.

\section{Batch procedure for the synthesis of 6,6-dimethylhept-1-en-4-yn-3-ol (3)}

To a stirred solution of 3,3-dimethylbutyne $(2,10.0 \mathrm{mmol})$ in dry cyclopentyl methyl ether $(6 \mathrm{~mL})$ butyl lithium $(2.5 \mathrm{M}$ in hexane, $4.00 \mathrm{~mL}, 10.0 \mathrm{mmol}$ ) was added at $0{ }^{\circ} \mathrm{C}$, under nitrogen atmosphere. The obtained mixture was stirred for $10 \mathrm{~min}$ and it was added dropwise to the cyclopentyl methyl ether $(10 \mathrm{~mL})$ solution of ethyl formate $(0.81 \mathrm{~mL}, 10.0 \mathrm{mmol})$ at $-78{ }^{\circ} \mathrm{C}$ between inert conditions. After $10 \mathrm{~min}$ stirring vinylmagnesium bromide (1 M in THF, $12.0 \mathrm{mmol}, 12 \mathrm{~mL}$ ) was added directly and after an additional $10 \mathrm{~min}$ stirring it was allowed to warm to room temperature. Saturated $\mathrm{NH}_{4} \mathrm{Cl}$ $(30 \mathrm{~mL})$ was added to the mixture and was extracted with cyclopentyl methyl ether $(3 \times 20 \mathrm{~mL})$. The combined organic layers were dried over anhydrous $\mathrm{Na}_{2} \mathrm{SO}_{4}$. Purification was performed by fractionated distillation to yield $3(10 \mathrm{Hgmm}$, $\left.60-62^{\circ} \mathrm{C}\right)$ as a pure colorless oil $(1.01 \mathrm{~g}, 79 \%) .8 \mathrm{H}(500 \mathrm{MHz}$, CDCl3) 5.97 (ddd, J = 17.0, 10.1, $5.2 \mathrm{~Hz}, 1 \mathrm{H}), 5.44(\mathrm{~d}, \mathrm{~J}=$ $17.0 \mathrm{~Hz}, 1 \mathrm{H}), 5.19$ (d, J = 10.1 Hz, 1H), 4.86 (d, J = 4.9 Hz, $1 \mathrm{H}), 1.96(\mathrm{~s}, 1 \mathrm{H}), 1.23(\mathrm{~s}, 9 \mathrm{H}) \mathrm{ppm} . \delta \mathrm{C}(126 \mathrm{MHz}, \mathrm{CDCl} 3)$ 137.8, 116.0, 95.6, 77.5, 63.4, 31.1 (3C), $27.5 \mathrm{ppm}$.

\section{Batch-flow hybrid procedure for the synthesis of 4,4-dimethylpent-2-ynal (4)}

To a stirred solution of 3,3-dimethylbutyne $(2,10.0 \mathrm{mmol})$ in dry cyclopentyl methyl ether $(6 \mathrm{~mL})$ butyl lithium $(2.5 \mathrm{M}$ in hexane, $4.00 \mathrm{~mL}, 10.0 \mathrm{mmol}$ ) was added at $0{ }^{\circ} \mathrm{C}$, under nitrogen atmosphere, and the obtained mixture was stirred for $10 \mathrm{~min}$. This solution of lithiated $2(1 \mathrm{M})$ and a CPME solution $(1 \mathrm{M})$ of ethyl formate $(0.81 \mathrm{~mL}, 10.0 \mathrm{mmol})$ were mixed via a Y-junction (Supelco, PEEK for 1/8" OD tubing) using Asia Syringe pumps (Syrris Ltd., Royston, UK) at $-20{ }^{\circ} \mathrm{C}$ for a $42 \mathrm{~s}$ of residence time. After reaching steady state, the resulting mixture was quenched by $10 \% \mathrm{KH}_{2} \mathrm{PO}_{4}$, and was analyzed by gas chromatography (See Table 3 ).

\section{Batch-flow hybrid procedure for the synthesis of 6,6-dimethylhept-1-en-4-yn-3-ol (3)}

To a stirred solution of 3,3-dimethylbutyne $(2,10.0 \mathrm{mmol})$ in dry cyclopentyl methyl ether $(6 \mathrm{~mL})$ butyl lithium $(2.5 \mathrm{M}$ in hexane, $4.00 \mathrm{~mL}, 10.0 \mathrm{mmol}$ ) was added at $0{ }^{\circ} \mathrm{C}$, under nitrogen atmosphere, and the obtained mixture was stirred for 10 min. This solution of lithiated $2(1 \mathrm{M})$ and a CPME solution $(1 \mathrm{M})$ of ethyl formate $(0.81 \mathrm{~mL}, 10.0 \mathrm{mmol})$ were mixed via a Y-junction (PEEK for $1 / 8$ " OD tubing) using Asia Syringe pumps at $-20{ }^{\circ} \mathrm{C}$ for a $42 \mathrm{~s}$ of residence time. Afterwards, a cyclopentyl methyl ether solution $(0.6 \mathrm{M})$ of vinylmagnesium bromide ( $1 \mathrm{M}$ in THF, $12.0 \mathrm{mmol}, 12 \mathrm{~mL}$ ) was introduced to the reaction mixture via a second Y-junction at also $-20{ }^{\circ} \mathrm{C}$, which was followed by an additional $71 \mathrm{~s}$ of residence time at $0{ }^{\circ} \mathrm{C}$. After reaching steady state, the resulting mixture was quenched by saturated $\mathrm{NH}_{4} \mathrm{Cl}$, and was analyzed by gas chromatography (See Table 4).

\section{Conclusion}

In conclusion, a reproducible and safe procedure was developed for synthesis of 6,6-dimethylhept-1-en-4-yn-3-ol key intermediate of terbinafine via a three-step batch-flow hybrid process. Using the flow technique, next to eliminating the toxic acrolein, there was no need for extremely low temperatures, the volatile aldehyde intermediate was carried on without isolation and the overall conversion proved to be $10 \%$ higher than between batch conditions. The precise control of the reaction variables improved selectivity while maintaining relatively high yield as compared to the corresponding batch procedures. The productivity of 6,6-dimethylhept-1-en-4-yn-3-ol was calculated to be $5 \mathrm{mmol} / \mathrm{min}$ in this newly developed batch-flow set-up. The elaborated procedure allows stopping at the level of aldehyde during the addition of the lithiated species to the ethyl formate without using any additives. That crucial step can be accomplished between $-20^{\circ} \mathrm{C}$ to $0{ }^{\circ} \mathrm{C}$ instead of the literature suggested $-78^{\circ} \mathrm{C}$ [26], using much less "cold energy", which is advantageous for possible industrial large scale production. The rate and required temperature $\left(0^{\circ} \mathrm{C}\right)$ of vinylmagnesium bromide addition step fits well to the previous organometallic reactions, thus high productivity and selectivity can be realized in the first batch-flow hybrid, three-step organometallic synthesis of 6,6-dimethylhept-1-en-4-yn-3-ol.

Acknowledgments This work was performed in the frame of FIEK_161-2016-0007 project, implemented with the support provided from the National Research, Development and Innovation Fund of Hungary, financed under the FIEK_16 funding scheme. T.H. is grateful for the scholarships of József Varga Foundation (2019/004). 
Funding Open access funding provided by Budapest University of Technology and Economics.

Open Access This article is licensed under a Creative Commons Attribution 4.0 International License, which permits use, sharing, adaptation, distribution and reproduction in any medium or format, as long as you give appropriate credit to the original author(s) and the source, provide a link to the Creative Commons licence, and indicate if changes were made. The images or other third party material in this article are included in the article's Creative Commons licence, unless indicated otherwise in a credit line to the material. If material is not included in the article's Creative Commons licence and your intended use is not permitted by statutory regulation or exceeds the permitted use, you will need to obtain permission directly from the copyright holder. To view a copy of this licence, visit http://creativecommons.org/licenses/by/4.0/.

\section{References}

1. Allmendinger T, Angst C, Kaffunkel H (1995). J Fluorine Chem $72: 247-253$

2. Skoda EM, Davis GC, Wipf P (2012). Org Process Res Dev 16:2634

3. Lumbroso A, Cooke ML, Breit B (2013). Angew Chem Int Ed 52: 1890-1932

4. Tshibalonzaa NN, Monbaliu J-CHM (2017). Green Chem 19: 3006-3013

5. Li X, Zhang Y (2016). ACS Catal 6:143-150

6. Besemer B, Grassberger M, Ghazzouli I, Stütz A, Sandoz AG, 1989, CH671015

7. Faigl F, Barcza T, Ágai B, Töke L (1999). ACH - Models in Chemistry 136:593-598

8. Stuetz A, Petranyi G (1984). J Med Chem 27:1539-1543

9. Balfour JA, Faulds D (1992). Drugs 43:259-284

10. Ryder NS (1992). Br J Dermatol 126:2-7

11. Gupta AK, Shear NH (1997). J Am Acad Dermatol 37:979-988

12. Darkes MJM, Scott LJ, Goa KL (2003). Am J Clin Dermatol 4:3965

13. Grassberger, M.; Petrányi, G., 1982, FR2496103A1

14. Meki, N.; Nishida, K. N. Sh.; Imahase, T., 1989, EP341048A1

15. Danon, E.; Friedman, O.; Kaspi, J., 2002, EP1174407A2

16. Plutschack MB, Pieber B, Gilmore K, Seeberger PH (2017). Chem Rev 117:11796-11893

17. Britton J, Raston CL (2017). Chem Soc Rev 46:1250-1271

18. Bédard A-C, Adamo A, Aroh KC, Russell MG, Bedermann AA, Torosian J, Yue B, Jensen KF, Jamison TF (2018). Science 361: $1220-1225$

19. Adamo A, Beingessner RL, Behnam M, Chen J, Jamison TF, Jensen KF, Monbaliu J-CM, Myerson AS, Revalor EM, Snead $\mathrm{DR}$ et al (2016). Science 352:61-67

20. Baumann M, Baxendale IR (2015). Beilstein J Org Chem 11:1194 1219

21. Glasnov T (2016) Continuous-flow chemistry in the research laboratory. Springer International Publishing AG, pp 21-68

22. Gutmann B, Cantillo D, Kappe CO (2015). Angew Chem Int Ed 54:6688-6728
23. Rahman MT, Wirth T (2018) Flow chemistry for the synthesis of heterocycles. Springer International Publishing AG, pp 343-373

24. Neyta NC, Riley DL (2018). React Chem Eng 3:17-24

25. Fitzpatrick DE, Battilocchio C, Ley SV (2016). Org Process Res Dev 20:386-394

26. Knight DW, Rost HC, Sharland CHM, Singkhonrat J (2007). Tetrahedron Lett 48:7906-7910

27. Bowling NP, Burrmann NJ, Halter RJ, Hodges JA, McMahon RJ (2010). J Org Chem 75:6382-6390

28. Peil S, Fürstner A (2019). Angew Chem Int Ed 58:18476-18481

29. Yamaguchi M, Shibato K, Fujiwara S, Hirao I (1986). Synthesis 5: 421-422

30. Bohlmann F (1953). Chemische Berichte 86:63-69

31. Belot S, Quintard A, Krause N, Alexakisa A (2010). Adv Synth Catal 352:667-695

32. Li H, Grassi D, Guénée L, Bürgi T, Alexakis A (2014). Chem Eur J 20:1-14

33. Zhou B, Wu Q, Dong Z, Xu J, Yang Z (2019). Org Lett 21:3594 3599

34. Aycock DF (2007). Org Process Res Dev 11:156-159

35. Pace V, Hoyos P, Castoldi L, Domnguez de Mara P, Alcántara AR (2012). ChemSusChem 5:1369-1379

36. Azzena U, Carraro M, Pisano L, Monticelli S, Bartolotta R, Pace V (2019). ChemSusChem 12:40-70

37. Watanabe K, Yamagiwa N, Torisawa Y (2007). Org Process Res Dev 11:251-258

38. Bana P, Örkényi R, Lövei K, Lakó Á, Túrós GI, Éles J, Faigl F, Greiner I (2016). Bioorg Med Chem 25:6180-6189

39. Hessel V, Löwe H, Schönfeld F (2005). Chem Eng Sci 60:24792501

40. Reckamp JM, Bindels A, Duffield S, Liu YC, Bradford E, Ricci E, Susanne F, Rutter A (2017). Org Process Res Dev 21:816-820

Publisher's note Springer Nature remains neutral with regard to jurisdictional claims in published maps and institutional affiliations.

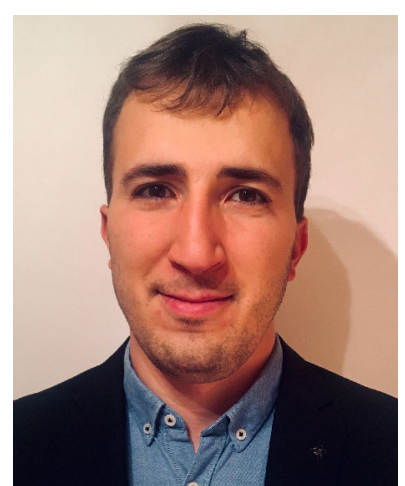

Tamás Hergert Graduated from the Budapest University of Technology (BUTE) and Economics in 2015 as an engineer in pharmaceutical industry. He received his $\mathrm{PhD}$ in 2018. He became a Research Associate at the Center for University-Industry Cooperation (BME-FIEK) in 2018. His main research topics include the synthesis of heterocycles and APIs via organometallic and continuous flow chemistry. 